\title{
Molecular diagnosis and clinical onset of Charcot-Marie-Tooth disease in Japan
}

Akiko Abe, Chikahiko Numakura, Kazuki Kijima, Makiko Hayashi, Taeko Hashimoto and Kiyoshi Hayasaka

Journal of Human Genetics (2011) 56, 751; doi:10.1038/jhg.2011.81

Correction to: Journal of Human Genetics (2011) 56, 364-368; doi:10.1038/jhg.2011.20; published online 17 February 2011

In Table 3, one of the novel mutations in GJB1 gene, c.124A > T/ Ser42Cys, was incorrectly given as c.124A $>$ C/Ser42Cys, and genotype, heterozygote, was incorrectly given as hemizygote. A novel mutation in GDAP gene, $($ c.740C $>\mathrm{T})+(\mathrm{c} .845 \mathrm{G}>\mathrm{A}) /(\mathrm{Ala} 247 \mathrm{Val})+(\mathrm{Arg} 282 \mathrm{His})$ was incorrectly given as $(\mathrm{c} .740 \mathrm{C}>\mathrm{A})+(\mathrm{c} .845 \mathrm{G}>\mathrm{A}) /(\mathrm{Ala247 \textrm {Val } ) +}$ (Arg282His).

The authors would like to apologize for these errors. 